\title{
An Investigation into Regular Recruit Wastage from the British Army, 1988
}

\author{
Maj T O Jefferson \\ MSc, MRCGP, MFPHM, DRCOG, DTM\&H, RAMC* \\ RAMC Training Group, Keogh Barracks, Ash Vale, Hants GU12 5RQ
}

SUMMARY: A study was made of recruit medical discharges in the British Army in 1988 with the aim of ascertaining the $\bar{\partial}$ number of medical discharges amongst recruits. AFBs 6863 (Notification of Discharge of a Regular Recruit) were used as the source of data. Recruit medical wastage rate for 1988 was 897 cases, or $16.7 \%$ of all known discharges. Three types of medical discharges were present. Four hundred and ninety-six Type 1 or concealed discharges, $(9.2 \%$ of discharges for all reasons) were made up of cases who had not been boarded and had mainly been discharged under QR 9.381 (defect of $\mathrm{N}$ enlistment). Two hundred and seventy-five Type 2 discharges (5.1\% of discharges for all reasons) represented boarded cases discharged under QR 9.385 (ceasing to fulfil medical requirements). One hundred and twenty-six Type 3 discharges. ( $2.3 \%$ of all discharges) were boarded cases mainly discharged under QR 9.381 (defect of enlistment). As all discharges under parargraphs other than QR 9.385 are given administrative discharge outflow code, only the 275 Type 2 discharges $\stackrel{\omega}{\circ}$ (or 31.7\% of medical discharges) appeared on the Army's own source of medical data, the TRIMEDS database. This had $\bar{\Xi}$ the effect of concealing the majority of those discharges caused by conditions predating enlistment therefore decreasing $\mathcal{F}^{\circ}$ the number of known false negatives not detected at recruiting medicals.

The biggest causes of discharge were conditions of the lower limbs and back $(54.5 \%$ of medical discharges), a $\vec{\omega}$ conglomerate of minor categories of pathology $(14.6 \%)$, asthma $(9.6 \%)$ and deformities $(7.4 \%)$. Within each type the $\grave{c}$ bulk of the discharges was concealed in Type 1 discharges especially for conditions predating enlistment.

The mean time of stay in the Army was much higher for Type 2 discharges (276.3 days) probably caused by extra time $\omega$ for treatment, boarding and obtaining MOD authority for discharge. Several faults in the DAR database were discovered $\bigcirc$ and comments are made on the quality of form filling.

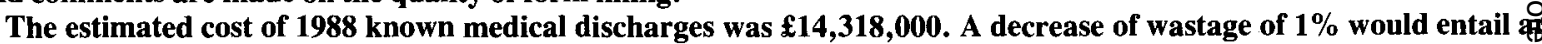
average saving of $£ 143,000$ a year and the delay of enlistment of all candidates with a childhood history of asthma to the age of 22 would entail a saving of $£ 318,000$.

Concentration of recruit screening would bring further efficiency savings. Recommendations based on the stuci $\bar{y}$ findings are made.

\section{Introduction}

Each year the Army seeks to replace manpower wastage by attracting members of the public in the appropriate age groups and with the necessary qualifications.

Preliminary enquiries and initial selection are carried out at Army Career Information Offices (ACIOs) distributed around the country.

Approximately 20,000 applicants are sent each year to training establishments to commence recruit training. Approximately 5,000 of these are subsequently discharged as unsuitable for service as trained soldiers.

Authority for all regular recruit discharges originates from the Queen's Regulations (QR) for the Army(1).

There are two main sections under which a regular recruit with a medical problem may be discharged.

The first is $Q R$ 9.381, dealing with the defect in enlistment procedure. Under this paragraph a soldier who after enlistment has been found to be medically unfit on the basis of a condition that pre-existed the soldier's enlistment may be discharged on the authority of his Commanding Officer. Such a condition may have been overlooked, inappropriately assessed or not declared during the soldier's recruitment phase.

The second comprises QR 9.385, 9.386 and 9.387. The most important of which is QR 9.385 (ceasing to fulfil Army medical requirements) as it applies also to recruits

undergoing basic training whose medical category fa传 below entry standards but whose change in medical category status has taken place since enlistment as a result of a disease or injury acquired during service. The $\mathbb{\perp}$ MOD is the authority for discharge.

Other sections of QR may be used as authority to discharge recruits although they also apply to other soldiers. These are QR 9.391 (discharge having applied to determine service or claim discharge) and QR 9.422 (termination of service on compassionate grounds) where the recruit is discharged by the Commanding Officer at the recruit's request. If a discharge on medical grounds is decided, Commander Medical of the District $\underset{\mathbb{D}}{\mathbb{D}}$ decides under which QR paragraph the discharge will $\underset{F}{\vec{F}}$ take place.

The recruit's Commanding Officer subsequently actions the discharge according to the QR paragraph to 8 . be used. The most important documents are the FMED $₹$ 23 which summarizes the findings of the board and the 을 reason for discharging the recruit, and Army Form 6863 D (AFB 6863) (notification of discharge of a regular recruit). A copy of the FMED 23 is sent to the Ministry $\vec{N}$ of Defence Medical Statistics Branch while the original 5 is dispatched with the whole of the former recruit's 0 documentation to the relevant Manning and Records $\underset{\omega}{\mathrm{W}}$ Office. Each record office subsequently sends medical

* Now Corso di Stato Maggiore, Scuola di Guerra, via Leopoli, 00058 Civitavecchia (Roma), Italy. 
documents relating to medical discharges to the Department of Health, and for each cause of discharge inputs into the Army's pay and records computerized system a code of discharge, known as an outflow code corresponding to the $\mathrm{QR}$ paragraph under which the recruit is discharged.

Regulations concerning the assignment of outflow codes are laid down officially and are the same throughout the Army(2). All discharges of recruits are notified by the training unit to the Directorate of Army Recruiting 2 (DAR 2) using AFB 6863, entered onto a central database and audited periodically. The front of the form analyses the reasons for discharge, including a summary of the PULHHEEMS ratings. The reverse consists mainly of the pen picture of the recruit and of the cause of discharge. The DAR 2 database contains information relating to each form up to but not including the brief history of the circumstances leading to the recruit's discharge. The main discharge procedures for regular recruits who have served less than 6 months are summarised in Figure 1.

Jefferson(3) reviewed the data available on the TRIMEDS database relating to male medical discharges for the years 1979-1986 and demonstrated that medical discharges were highest amongst the most junior and youngest (below the age of 30) members of the Army, especially the infantry, and were increasing each year throughout the study period. Because the TRIMEDS coding procedures were unable to distinguish between trained soldiers and recruits and because of the possible use of the administrative discharge procedure, no separate data were available on recruit discharges and the data presented were likely to be an underestimate.

The analysis of the problem of reduction of recruit wastage has been hampered by the lack of hard data on medical wastage of recruits and its financial implications. The discharge of recruits under the administrative procedure may imply an underestimation of the incidence of recruit medical discharges.

TRIMEDS represents the Ministry of Defence's only source of information for all matters concerning medical aspects of discharges and is used to repond to a wide variety of queries including Parliamentary questions.

The aim of the study was to ascertain any underestimation of regular recruits discharged for medical reasons from the British Army and to analyse the implications. The objectives of the study were:

a) To survey the circumstances of all recruit discharges from the British Army for the period 1 January 1988-31 December 1988. (The term recruit includes both senior or adult recruits and junior recruits).

b) To identify and count those discharges which had causes of a non medical nature.

c) To identify those discharges which are primarily medical in nature (henceforth referred to as medical discharges regardless of the discharge procedure) and had been effected using the medical discharge procedure and those effected via the administrative discharge

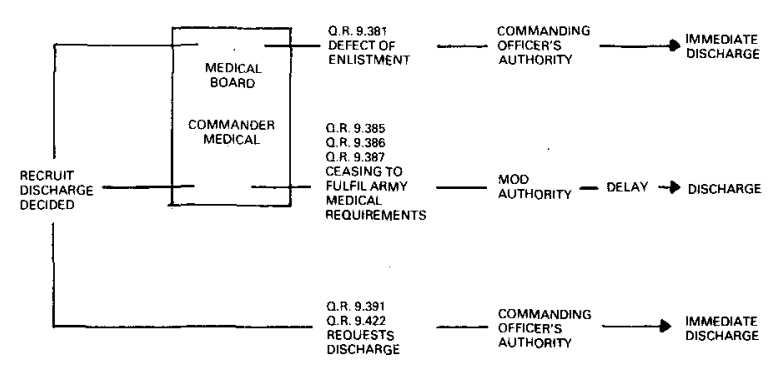

Fig 1. Summary of main discharge procedures for regular recruits below 6 months service for medical reasons. Based on Queen's Regulations for the Army (Q.R.). For explanation see text.

procedure.

d) To analyse the causes of all medical discharges identified.

e) To recommend, if appropriate, changes in the discharge procedure in order to provide an accurate yearly estimate of medical discharges.

f) To assess the implications of the findings of the study for recruiting and retention of recruits in the Army in the 1990s.

g) To assess the financial implications of the 1988 wastage.

\section{Methods}

To survey the circumstances of all regular recruits discharges, all AFB 6863 received by DAR 2 bearing effective discharge dates between the period 1 January 1988-31 December 1988 were copied, collected and scrutinized. On completion of the preliminary phase of collection of AFBs 6863 all forms were counted. There were 5,066 forms available for the study, but the DAR 2 database contained only 4,995 entries for 1988 . The study forms were checked to ascertain that they contained no duplicates. None was found.

This raised the serious possibility of some forms having been received by DAR 2 but not included in the database. Exhaustive enquiries failed to reveal why this might be so. It was concluded that there was no reliable data on just how many recruits had been discharged, although in previous years the total varied between 5,000 and 6,000 . It was discovered that forms relating to discharges of recruits from two Corps, effected during the period January to September 1988 had been destroyed. Further enquiries revealed no evidence of a bias towards medical discharges; the possibility of a systematic bias could not be discounted; for instance the missing forms could contain a preponderance or scarcity of medical discharges and these could originate from specific units which experience atypical patterns of discharge causes. It was also clear that all available forms had not been sent at the beginning of the study thus increasing the possibility of bias. This is the reason for the two-phase analysis of data (see below). All forms 
were scrutinized initially to ensure that they fulfilled the entry criteria and assigned a study number. The forms were divided initially into medical and non-medical (administrative) discharges. The criteria for categorisation as medical discharges have been defined. The non-medical discharges were counted and set aside. No further analysis of them was undertaken. Data from all medical discharges were extracted and entered onto a database on a microcomputer. The variables which were examined were:

- training unit,

- interval in days between date of the recruit joining the unit and the date the recruit being discharged,

- the manner of discharge,

- the medical cause of discharge as described in the form.

To discover whether the TRIMEDS data underestimates the number of recruits discharged for medical reasons during 1988 , the medical discharges identified by inspection of the forms were compared to the list of medical discharges for 1988 on TRIMEDS using the surname and each soldier's unique service number.

It is known(3) that rank codes in TRIMEDS do not distinguish between recruits and Private soldiers. The rank code groupings are in fact Junior and Apprentice and Private, which includes adult recruits. It was assumed that all the discharges appearing on the TRIMEDS printout and not matched by the study medical discharges were discharges in the rank of Private. A summary of causes of discharge broad diagnostic groups was compiled. Summary statistics for the interval between joining of unit and discharge were calculated by the type of discharge (known or concealed medical discharge). Frequency tabulations of diagnostic cause were produced by type of discharge. A comparison of the relative frequency of discharge causes in the two groups was carried out. The reasons for any medical discharges not appearing on TRIMEDS were sought by reviewing the process of coding and entering data on the TRIMEDS database as well as scrutinising the AFBs 6863 relating to concealed medical discharges. The review of the coding procedure was carried out using semi-structured interviews with personnel working on TRIMEDS at Medical Statistics Branch.

In order to assess the possible bias problem a supplementary search was instituted for possible missing forms by matching 1,100 forms in the possession of DAR 2 with all 5,066 in the custody of the author and comparing the medical discharge variables contained in the forms already in the study (henceforth described as Phase 1) with the ones identified in a possible missing subset (Phase 2). Following the discovery of the possibility of missing forms it became clear that what was originally thought to be a whole population of discharges was revealed to be a sample which cannot be considered strictly random.

In the results section the combined results from both phases are presented as well as the results of the comparison of data from Phases 1 and 2 to identify any bias. The following statistical methods were used in the analysis of combined data from Phases 1 and 2.

For those discharges judged to be primarily medical in nature, the training unit, diagnostic cause of discharge and interval in days between joining the unit and discharge were entered onto the Statgraphics software package (held on an Apricot Xen-i micro computer running under MS-Dos). Each case was further classified by 'type' of medical discharge, namely:

Type 1 - discharges apparently effected without a medical board and not appearing on TRIMEDS.

Type 2 - discharges effected with a medical board and appearing on TRIMEDS.

Type 3 - discharges effected with a medical board but $\stackrel{\omega}{\omega}$ not appearing on TRIMEDS, although details of the board are held in the Medical Statistics Branch under the summary of the soldiers' medical documents.

Because the cases identified were not the complete set of 1988 discharges, $95 \%$ confidence intervals were calculated around the estimated percentages in each category. The parameters of interest are multinomially distributed and not independent so the most correct method is to calculate a simultaneous $95 \%$ confidence region. However as this is mathematically tedious an difficult to interpret, the parameters were individualo treated as binomially distributed and separate 95 confidence intervals were calculated using large samp normal approximation theory. Where only a few pars meters are involved (as here) this method is adequate A finite population correction was incorporated to allow for the large sample size relative to the assumed tot 3 population of 1988 discharged recruits $(4,5)$.

Summary statistics for the interval between joining of unit and discharge were calculated by Type of discharge. Frequency tabulations of diagnostic cause and of training unit were produced by type of discharge. This information was also presented in the form of frequency histograms and stacked bar charts.

The time intervals were compared between types of discharge using the distribution-free Mann-Whitney and Kruskal-Wallis tests because the data were non-normal, positively skewed, (as indicated using the KolmogorovSmirnov and chi-squared goodness of fit tests and standardised coefficients of skewness and kurtosis). Group variances were not homogeneous (Bartlett's and Cochran's $\mathrm{C}$ tests) and no one simple transformation (such as $\log$ or power) adequately normalized the data and stabilised group variances. Chi-squared statistics were used to examine the strength of association $\frac{0}{5}$ between type and (grouped) cause of discharge. $D$ Significance levels, p, equal to or less than 0.05 are considered to indicate statistically significant results. N The costs of wastage represented by known and unknown medical discharges of recruits were obtained 0 from previously calculated estimates of the cost of $\omega$ recruiting and processing each recruit who is subse- 
quently wasted up to the day of joining the training unit(3). The cost of training was estimated by calculating the recruit's pay and allowances plus the training cost.

As junior training costs are different from senior recruits', the cost of training and pay and allowances was calculated for each category of recruit. All daily costs were then multiplied by the total duration of the recruit's stay in the Army represented by the interval between joining unit and discharge and the total cost obtained.

For senior recruits the estimates of daily costs were available(3), whereas for junior recruits each junior unit provided estimates. Details of pay and average allowances were derived in the same manner.

\section{Results}

\section{A-(Phases 1 and 2 combined)}

A total of 5,363 discharges $(100 \%$ of known discharges) for all causes was identified, 5066 in Phase 1 and 297 in Phase 2. Of these 4,466 were non medical in nature $(83.3 \%)$ and $897(16.7 \%)$ were discharges for medical reasons.

Of the medical discharges $496(9.2 \%)$ were of Type 1 , $275(5.1 \%)$ of Type 2 and $126(2.3 \%)$ of Type 3 . This is summarised in Figure 2.

The 5,363 discharges represent less than $100 \%$ of the total 1988 figure as some records were destroyed and Phase 2 yielded 297 new discharges for all reasons from the matching of the 1,100 records from DAR with all the Phase 1 records in the author's possession.

It is therefore appropriate to construct confidence intervals around the above percentages incorporating a finite population correction.

Here an upper limit of 6,000 has been taken as the total 1988 population of discharged recruits. If the true

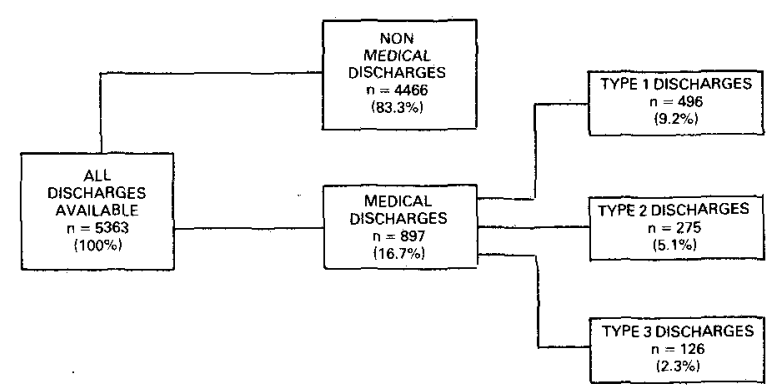

Fig 2. Breakdown of discharges of regular army recruits in the year 1 Jan-31 Dec 1988. Percentages in brackets are of total discharges.

Type 1 - Discharges of a medical nature apparently without a medical board and not effected under Q.R. 9.385-7.

Type 2 - Discharges of a medical nature with a medical board and effected under Q.R. 9.385-7.

Type 3 -Discharges of a medical nature with a medical board and not effected under Q.R. 9.385-7. figure were less than 6,000 the intervals would be narrower (and the estimated percentages more precise); if greater than 6,000 the intervals would be slightly wider than those estimated here. Approximate, individual, $95 \%$ confidence intevals are:

Type $1: 8.9 \%$ to $9.5 \%$

Type $2: 4.9 \%$ to $5.3 \%$

Type $3: 2.2 \%$ to $2.4 \%$

Non medical discharges: $83 \%$ to $83.6 \%$.

In Table 1 data for the interval between joining unit and discharge are summarised.

Two forms lacked the information on the interval between joining unit and discharge.

The total days the 895 discharges spent in the Army amounted to 132,459 . The Kruskal-Wallis and MannWhitney tests indicated that the interval was very significantly longer for Type 2 cases than either Type 1 or Type 3 cases and also that Type 3 cases had significantly longer intervals than those of Type 1 ( $p$ less than $10^{-6}$ throughout).

The chi-squared test was not particularly informative indicating only that a highly significant association existed between type and cause of discharge, but not where the specific features of interest were (these can be readily seen from the tabulation by grouped cause ofo discharge at Table 2).

The overall data are presented in histogram form (aळ the frequency of the causes of medical discharge) ing Figure 3.

Lower limb and back injuries overall represented the commonest cause of discharge in all types.

The overall second largest category of discharges was represented by a variety of low incidence conditions ophthalmic urological and dermatological. Because of resource constraints their analysis will take place at a later date. Tabulation of the principal discharge causes by discharge type is at Table 2 .

Table 1

Interval between joining unit and discharge (in days). Summary descriptive statistics.

\begin{tabular}{lcccc}
\hline & Type 1 & Type 2 & Type 3 & $\begin{array}{c}\text { All } \\
\text { Medical } \\
\text { Discharges }\end{array}$ \\
\hline $\begin{array}{l}\text { Number of cases } \\
\text { Number with } \\
\text { interval recorded }\end{array}$ & 496 & 275 & 126 & 897 \\
Days: & 495 & 275 & 125 & 895 \\
Total & 40903 & 75986 & 15570 & 132459 \\
Mean & 82.6 & 276.3 & 124.6 & 148 \\
Standard Deviation & 79.7 & 133.9 & 104.3 & 134.2 \\
Median & 60 & 250 & 92 & 100 \\
Range & 504 & 810 & 539 & 826 \\
Interquartile Range & 89 & 153 & 122 & 182 \\
\hline
\end{tabular}


Table 2

Tabulation of Discharges by Cause and Type. In brackets are Percentages by Type.

\begin{tabular}{lcccc}
\hline $\begin{array}{l}\text { Discharge } \\
\text { Cause }\end{array}$ & $\mathbf{1}$ & $\mathbf{2}$ & $\mathbf{3}$ & $\begin{array}{c}\text { Row } \\
\text { Total }\end{array}$ \\
\hline Deformities & 51 & 8 & 7 & 66 \\
& $(77.3)$ & $(12.1)$ & $(10.6)$ & $(7.4)$ \\
Neuro/Psychiatric & 41 & 5 & 8 & 54 \\
& $(75.9)$ & $(9.3)$ & $(14.8)$ & $(6.1)$ \\
Accidents & 25 & 16 & 4 & 45 \\
& $(55.6)$ & $(35.6)$ & $(8.9)$ & $(5.0)$ \\
Hearing & 14 & 3 & 8 & 25 \\
Lower Limbs/Back & $(56.0)$ & $(12.0)$ & $(32.0)$ & $(2.8)$ \\
& 224 & 197 & 65 & 486 \\
Asthma & $(46.1)$ & $(40.5)$ & $(13.4)$ & $(54.5)$ \\
& 58 & 12 & 16 & 86 \\
Other & $(67.4)$ & $(14.0)$ & $(18.6)$ & $(9.6)$ \\
& 82 & 30 & 18 & 130 \\
& $(63.1)$ & $(23.1)$ & $(13.8)$ & $(14.6)$ \\
\hline Column Total & 495 & 271 & 126 & 892 \\
& $(55.5)$ & $(30.4)$ & $(14.1)$ & $(100.00)$ \\
& & & & \multicolumn{3}{c}{ Significance } \\
\hline Chi-squared & Degrees of & \multicolumn{5}{c}{ pless than 0.000001 } \\
\hline Freedom & 12 &
\end{tabular}

NB. In 5 cases no cause of discharge was available.

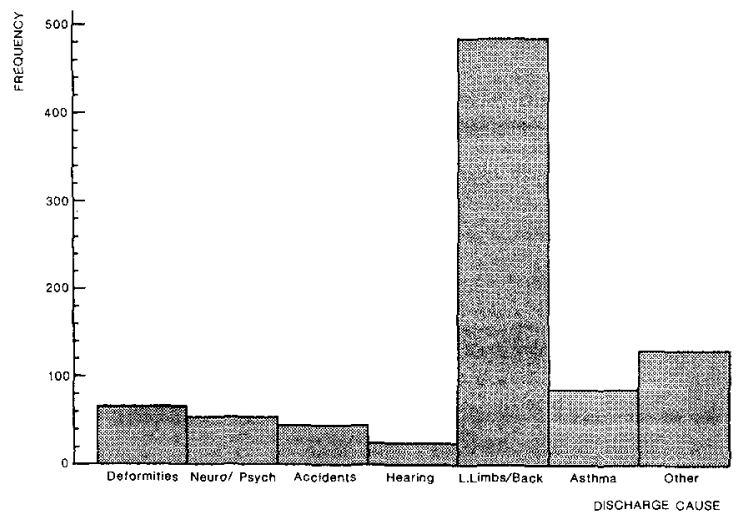

Fig 3. Medical discharges of regular army recruits for the year 1 Jan - 31 Dec 1988 by diagnostic cause and all types. For explanation see text.

Lower limb and back injuries connected with overuse accounted for the biggest category of causes of discharges in all types. The second single largest cause of discharge was represented by asthma (including all wheezy chest conditions which rendered the recruit incapable of carrying out physical activity). The majority of asthma discharges were in Type 1 . These accounted for $67.4 \%$ of asthma discharges.
Analogous data are presented in Fig 4, by causes of medical discharges broken down by type incidenc within each overall cause.

\section{$B$-(Comparison of Phases 1 and 2)}

There were 5,066 discharges in Phase 1 of which 4,21 were non medical and 849 medical in nature.

In Phase 2 an additional 297 discharges were identifie of which 249 were non-medical and 48 medical. The ratiof of medical to non-medical discharges was $1: 5$ in bottle Phases, respectively 849:4,217 and 48:249.

The percentages of medical discharges by type are्? presented in Table 3, where the differences were notp statistically significant and were broadly similar im frequency.

Analysis of the interval between joining the unit and discharge suggested that the average (mean and median values are higher for Phase 2, particularly for Type $\frac{5}{3}$ cases, although these differences were not statistically, significant (p greater than 0.05, Mann-Whitney rank tes $\overrightarrow{\mathrm{t}}$ and two-way ANOVA by type and phase).

Ther costs of wastage were calculated with severaw assumptions. Possible variables that should be taken into consideration include the cost of medical treatmeng (this varies from case to case), the recruit's output before discharge (unlikely to be great as even simplo tasks such as standing guard are barred to recruits) and the cost of medical pensions if applicable. Some of the were not readily obtainable, especially as an average others were unavailable given the constraints of study.

Total costs of all the 1988 known discharges, based estimates where appropriate, were as follows.

The cost of attracting and recruiting each soldier to the Army is estimated to be $£ 1,250(6)$. The 89 , discharges in 1988 represented a total cost of $£ 1,121,250$. .

The total time spent in the Army by the adult recruits discharged in 1988 was 85,396 days. Since in 1988 the

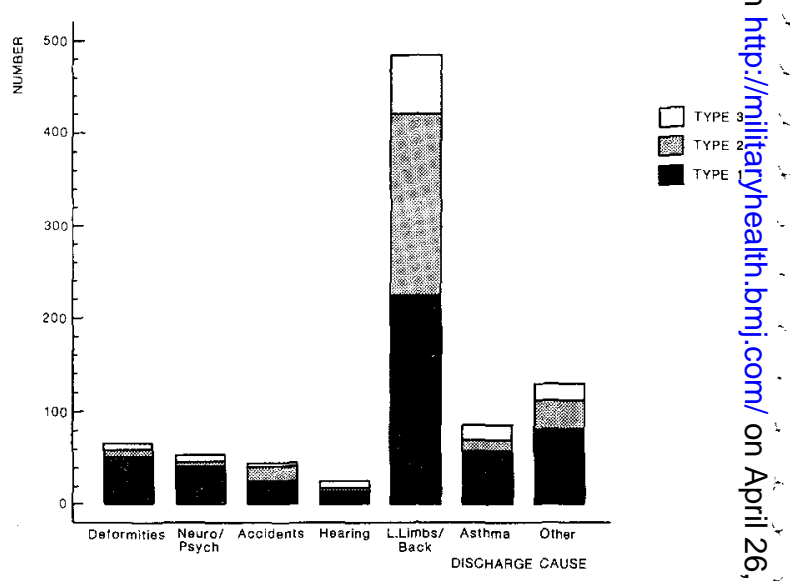

Fig 4. Medical discharges and type of discharge of regular army recruits for the year 1 Jan-31 Dec $1988 \mathrm{~W}$ For explanation see text. 


\section{Table 3}

\section{Comparison of Medical Discharges and All Discharges} by Type and Phase

\begin{tabular}{|c|c|c|c|c|}
\hline \multicolumn{5}{|c|}{ All Medical Discharges } \\
\hline & Type 1 & Type 2 & Type 3 & \\
\hline Phase 1 & $\frac{472}{849}=56 \%$ & $\frac{263}{849}=31 \%$ & $\frac{114}{849}=13 \%$ & $\begin{array}{l}\text { Chi- } \\
\text { Squared: }\end{array}$ \\
\hline Phase 2 & $\frac{24}{48}=50 \%$ & $\frac{12}{48}=25 \%$ & $\frac{12}{48}=25 \%$ & $\begin{array}{l}\text { pgreater } \\
\text { than } \\
0.05\end{array}$ \\
\hline \multicolumn{5}{|c|}{ All Discharges } \\
\hline Phase 1 & $\frac{472}{5066}=9 \%$ & $\frac{263}{5066}=5 \%$ & $\frac{114}{5066}=2 \%$ & $16 \%$ \\
\hline Phase 2 & $\frac{24}{297}=8 \%$ & $\frac{12}{297}=4 \%$ & $\frac{12}{297}=4 \%$ & $16 \%$ \\
\hline
\end{tabular}

total daily cost of an adult recruit was $£ 107$ a day( 3 ) (cost of training and pay and allowances), the total cost was $£ 9,137,372$.

Junior soldiers and Junior Leaders (whose costs and pay and allowances are comparable) discharged for medical reasons in 1988 spent a total of 31,558 days in the Army at an average of $£ 96$ a day. Their total cost was $£ 3,029,568$.

Apprentices subsequently discharged spent 14,719 days in the Army. Their average daily cost was $£ 70$. This was a mean figure of costs as different trades within the Apprentice cadre were paid differently. Their total cost was $£ 1,030,330$. The total cost of discharges was therefore $£ 14,318,520$.

\section{Discussion}

Six hundred and twenty-two (69.3\%) of the 897 medical discharges in recruits for the year 1988 were not recognisable as such on TRIMEDS database. The hypothesis that numbers of recruit medical discharges are underestimated was therefore confirmed. This was a sizeable underestimation (up to $2 / 3$ of yearly discharges) and called into question the reliability of TRIMEDS as a record of recruit discharges.

The introduction of bias caused by the missing forms did not seem likely given the results of the comparison between data from the two phases, although the absence of some AFBs 6863 still cannot be accounted for.

As causes of discharge were broadly similar in both phases of the study, cause of discharge bias in the missing forms was unlikely. The standard of form filling was adequate in most cases except for the box relating to PULHHEEMS

The significant difference in retention time between each type of discharge may be a confirmation of the validity of such a subdivision. Type 1 discharges had the shortest time, suggesting that delays in Types 2 and 3 discharges might have occurred either because of the seriousness of different pathology, or because of the delay in referring, investigating, treating and boarding recruits.

Broad analysis of the causes of discharge by type does not support the view of a difference in the pathologies causing discharge, only perhaps their onset.

In the absence of more detailed data, not available from examination of the forms, the factors more likely to cause delay appeared to be the referral and boarding procedures and the delay in obtaining MOD clearance for QR 9.385 discharges. The author did not find any evidence in the pen pictures contained in the AFBs 6863 of the alleged practice of using paragraphs other than QR 9.385 to discharge quickly recruits who had or had not been boarded but who were clearly medically not up to standard.

If trainers were engaged in such a practice, this entailed deceit on a large scale, as at least a proportion of these trainers would have had to gloss over the practice or actually lie, but QR 9.381 may quite rightfully be used to discharge medical cases providedo the condition causing discharge predated enlistment.

In a minority of cases evidence was found that both QR 9.422 and QR 9.391 were used in the voluntary discharge of recruits awaiting medical boards. This appeared to be a legitimate procedure as the use of the regulation is not restricted to recruits with medicaf problems, provided they themselves ask to go.

It is unclear why Types $1 \mathrm{did}$ not appear to have beefo boarded. No board was mentioned in the pen picture and the PULHHEEMS box entry on the form was of such low quality as to be virtually useless. A detailed examination of the 496 medical records involved was beyond the resources of this study but may be considered for later work. The real differences in the means of the delay suggested a difference in types of discharges. Given the cost implications of such suggestions a further study in the causes of delay is needed to clarify matters.

The high mean (276.3) and standard deviation (133.9) for the days spent in the Army by Type 2 dischargees examplified the dilemma facing the Army. While it is necessary to try to retain injured recruits by allowing them time to recover and improve with treatment (so called "back-squadding"), this increases the training costs.

The answer may lie in improving selection, by for instance detecting at entry those recruits who have a preservice history of knee pain and bad recovery rates(3).

Two hundred and seventy-five discharges were known as such on TRIMEDS (although the rank coding would only have allowed proper classification for a small proportion of them). These only represented $30.6 \%$ of real medical discharges ascertained by this study. 
Broad analysis of procedures for discharge revealed that the vast majority of Types 1 and 3 discharges had been effected under QR 9.381 (defect of enlistment) with only a small proportion under QR 9.391 (discharge having applied to determine service or claim discharge) and QR 9.422 (termination of service on compassionate grounds).

In all cases the use of QR 9.381 appeared to be appropriate when judged by the discharge pen picture, as all had been effected for medical conditions predating enlistment. All Type 2 discharges appeared to have been effected under QR 9.385. This led the author to suspect that the basis of the inclusion on the TRIMEDS list of medical discharges was related to the use of the computerised outflow code. This was confirmed by staff at Medical Statistics who were under instruction(2) to consider as medical only those discharges bearing an outflow code appropriate to cases discharged under QR 9.385, 9.386 and 9.387. Therefore any discharge not effected under QR 9.385 appeared on all Army records as administrative, leading to a persistent underestimation of medical discharge in recruits. A further consequence of the TRIMEDS selection bias was a false picture of the prevalence of certain conditions.

For instance, asthma occupied the fourth place in order of frequency in Type 2 discharges, but when all types were analysed, asthma accounted for 86 discharges in 1988 and became the single second largest cause of discharge. Since 74 ( $86 \%$ of total) asthma cases were discharged under QR 9.381, asthma appeared on TRIMEDS as a minor cause of discharge, in what can be called a "TRIMEDS Iceberg" effect where the bulk of cases were hidden from view. The 12 Type 2 asthma cases according to the pen picture on AFB 6863 were described as of onset after enlistment and the 74 occult cases were described as of pre-service onset (and therefore correctly discharged under QR 9.381).

The use of QR 9.381 and the consequent classing of the discharge under the administrative outflow code lead to TRIMEDS underestimating the number of false negatives for asthma allowed to join the Service after ACIO screening. A glance at the pen picture of some of the 74 occult cases revealed that exercise triggered the majority of the asthmatic attacks upon which the discharge diagnosis was made. If Dickinson's(7) recommendations of rejecting individuals with asthma until they are 22 were to be fully implemented, assuming a high sensitivity of the entry screening test, this would result in a $40 \%$ reduction in discharges representing 29 cases in patients with a pre-service history of asthma in 1988. Provided an accurate history was taken and exercise testing carried out, this would save the Army approximately $£ 318,000$ of training costs. This figure excludes costs of medical treatment and was calculated as a $40 \%$ reduction in the 1988 overall costs of discharge in Types 1 and 3 (whose condition pre-dates service) of individuals with asthma $(£ 795,000)$.
To improve the precision of screening use could be made of the applicants' GP record in a manner similar to $\frac{\widehat{\Phi}}{2}$ insurance company enquiries with a form requesting $\stackrel{\varnothing}{\varnothing}$ details of the applicants' past medical history. These $\bigcirc$ enquiries should be administered and evaluated by aţ medical officer to preserve confidentiality.

An even more accurate screening process might be $\overrightarrow{\overrightarrow{\vec{s}}}$ obtained at purpose built and properly staffed Army $\vec{O}$ Training Centres (ATCs) as envisaged by the MOD.

It is possible for potential recruits to deny symptoms $\frac{\overline{\bar{N}}}{\mathrm{D}}$ although there is no evidence of this in the forms $\mathbb{\nabla}$ scrutinised in this study.

An alternative explanation for the bias in TRIMEDS is that of inaccuracy by the author of the pen picture, $\vec{O}$ especially as on some forms no mention is made of the $\overrightarrow{\vec{H}}$ recruit having been examined by a doctor.

Clarification of this point would entail a further study into the actual medical records of each dischargee; however the use of QR 9.381 for conditions apparently? or actually predating enlistment was correct and the bias $\vec{\omega}$ will not be eliminated until changes are made to the outflow coding procedure. The apparent lack of reliability of DAR 2's database is a cause of concern. $\omega$ Given the data from the APRE study(8) the estimated total number of discharges for 1988 is probably in the region of 5,500.

Valid policy decisions are based on good data, and the lack of data on medical discharges (compounded by the apparent lack of input of some 1988 discharges) wa aggravated by the fact that pen pictures on AFB 68.3 were not routinely loaded on the database. The authe found these the most useful part of the form, relating qualitiative as well as quantitative data on the cause discharge.

Diagnoses based on a simple set of codes such as the ones used for this study are relatively easy to devise.

Specially trained computer operators such as $\overrightarrow{\vec{F}}$ abstractors are more likely than doctors to allocate a $\frac{0}{3}$ definite diagnosis category to medical discharge $=$ summaries $(9)$. A relatively straightforward system of monitoring quality of data on recruit discharges may be set up by using a randomly retrieved sample. For instance, two-weekly checks of random AFBs 6863 ఖ could be carried out with the aim of checking the accuracy of the data contained in the database.

Type 2 discharges are the only medical discharges in $\frac{0}{\bar{F}}$ recruits which appear on the TRIMEDS printout, but because of the lack of a coding distinction between senior recruits and private soldiers, all appear in the class of rank "Private or below". This grouping is too vague to allow a distinction between what really are two 윽. separate occupational categories: adult soldiers with $\rightarrow$ their regimental service and senior recruits with their 8 ? week intensive training. Routine detection of the incidence of specific conditions is made more arduous ? and a separate code for Privates and Recruits is the $\tilde{O}$ simplest way of overcoming the problem.

The implications for resource wastage due to recruit 
discharges for medical reasons appear substantial. If wastage could be reduced by $1 \%$ or 9 cases a year, over $£ 140,000$ would be saved and perhaps by increasing the yield of entry screening and introducing economies of scale this could be easily achieved. Although this study only furnished partial estimates of the worth to the Army of its recruits, cost benefit analysis using these estimates is now viable.

The relatively strict entry criteria of cases to the study produced conservative discharge figures, but eliminated several sources of inaccuracy.

No evidence was found that certain medical discharges were effected under paragraphs other than QR 9.385 in order to avoid a medical stigma in the recruit's subsequent search for jobs. Such discharges may have existed in the non medical AFBs 6863, but only if a completely false statement had been made on the form.

\section{Recommendations}

The outflow coding procedures for discharges under paragraphs other than QR 9.385 9.386 and 9.387 urgently need changing especially with regard to discharges under QR 9.381. A medical outflow code should be assigned to these discharges and monitoring of all discharges in recruits using the pen picture should be instituted.

The coding issue should be examined by DMSD for onward transmission to the Army Pay \& Records Central Office. DAR 2 should ensure that forms are scrutinized before discharge categories are entered into the database.

Dickinson's recommendations of preventing known childhood asthmatics from joining until the age of 22 should be implemented forthwith.

Army From B 6368 should be altered with the introduction of a specific box for $Q R$ paragraph of discharge and diagnosis at discharge for medical cases.

Periodic quality control of the data on the database should be carried out for all discharges. Randomly retrieved items from the database should be compared with original AFBs 6863 . DAR staff should ensure that no data is destroyed.

The standard of AFB 6863 filling should be improved especially with regard to PULHHEEMS boxes. The importance of correct form filling should be stressed to all users.

All medical discharges regardless of QR discharge paragraph should have a cause of discharge box inserted on the database. Trained abstractors should fill in the box using a simple code based on data extracted from the description of the circumstances leading to the discharge (Section D of the AFB 6863).

A different rank code for Privates and adult Recruits should be instituted for inclusion on TRIMEDS in collaboration with the Army Pay \& Records Central Office.

Broad changes to the recruiting medical procedures should await the results of Major Edmondson-Jones' study into ACIO medicals. However the MOD proposal of concentration of screening procedures in order to achieve greater efficiency is supported by the findings of this study.

Until ATCs are properly established all recruit medicals could be carried out in a few centralised well staffed centres around the country.

\section{Acknowledgements}

The author would like to thank the many people who provided advice and information, especially Brigadiers Bill Dodd and Julian Lewthwaite, Colonels Tony Harwood, John Tinsley and Chris Box, Major Paul Edmondson-Jones, Drs Martin McKee and Jenny Roberts, Mrs Margaret Sims and Mr Colin Hunt. Without their assistance this project would not have been possible.

\section{REFERENCES}

1. The Queen's Regulations for the Army 1975. London: Her Majesty's Stationery Office, 1975.

2. Regulations for the Army Pay Services, Volume 2 part 2 sections 4-7. Royal Army Pay Corps.

3. JEFFERSON T O. An investigation of Medical Discharges from the British Army 1979-1986. J R Army Med Corps 1989; 3: 115-123.

4. Pollard J H. A handbook of Numerical and Statistical Techniques. Cambridge University Press, pages 212-217.

5. Armitage P, Berry G. Statistical Methods in Medical Research. Blackwell Scientific Publications, pages 84-85 and $115-118$.

6. Ministry of Defence. Manning and Recruiting in the Lean Years of the 90s (the Marilyn Report), 1988.

7. Dickinson J G. Asthma in the Army: A Retrospective Study and Review of the Natural History of Asthma and its Implications for Recruitment. J R Army Med Corps 1988; 134: 65-72.

8. Box C J. A Survey of Overuse Lower Limb Injuries in Army Recruit Training - Phase 2. Army Personnel Research Establishment Report. APRE 1989; (in press).

9. MacKenzie E J, Shapiro S, Eastham J N. Rating AIS Severity Using Emergency Department Sheets Versus Inpatient Charts. J Trauma 1985; 25: 984-988. 